\title{
Exploration, exploitation and innovation performance: Disentangling the evolution of industry
}

\author{
Pilar Bernal \\ Facultad de Economía y Empresa \\ University of Zaragoza \\ Gran Vía 2, 50005 Zaragoza, Spain \\ pbernal@unizar.es \\ Corresponding author \\ Juan P. Maícas \\ Facultad de Ciencias Sociales y Humanas \\ University of Zaragoza \\ C/ Ciudad Escolar, s/n, 44003 Teruel, Spain \\ jpmaicas@unizar.es \\ Pilar Vargas \\ Facultad de Ciencias Empresariales \\ University of La Rioja \\ Cigüeña 60, 26005 Logroño, Spain \\ pilar.vargas@unirioja.es
}

\begin{abstract}
The evolution of industry has recently attracted the attention of scholars studying the relationships between exploration and exploitation strategies and innovation performance. Surprisingly, although extant research has already acknowledged its multidimensional character, it has only been analyzed in an aggregate fashion. In this paper, we distinguish two components of the evolution of industry, the pace of market evolution and the pace of technology evolution, and we elaborate on their different impacts in the context of exploration and exploitation strategies. More precisely, we argue that while a rapid pace of technology evolution has opposite impacts on the relationships between exploration (positive), exploitation (negative) and innovation performance, a rapid pace of market evolution positively affects both exploration and exploitation. Our findings provide substantial support for our prediction using a large panel of Spanish innovating firms for the period 2008-2012.
\end{abstract}

Exploration; Exploitation; Technology evolution; Market evolution; Industry evolution 


\section{INTRODUCTION}

The study of how exploration and exploitation strategies affect innovation performance has become a popular topic in strategic management literature (Rothaermel and Deeds, 2004; Greve, 2007). In recent years, our knowledge has evolved from the stream of research that analyzes the relationships between exploration, exploitation and innovation performance (Faems, Van Looy and Debackere, 2005) to a more recent line that suggests that these relationships should be studied from a contingency perspective (Jansen, Van den Bosch and Volberda, 2006; Yang and Li, 2011).

Our point of departure is to consider that, given their opposite natures, the factors explaining the relationships between exploration and exploitation and innovation performance are not necessarily the same (Mom, Van den Bosch and Volberda, 2007). This has opened a new line of research focused on a more granular and individual study of exploration and exploitation strategies (Yamakawa, Yang and Lin, 2011; Yang and Li, 2011).

The contingent nature of exploration and exploitation strategies has begun to be addressed in recent research. Organizational age (Rothaermel and Deeds, 2004; Yamakawa et al., 2011) and the size of the firm (Cao, Gedajlovic and Zhang, 2009) are two salient examples of contingencies of the impact of exploration and exploitation strategies on innovation performance. However, the environment is probably one of the dimensions that has recently attracted the interest of scholars most (Auh and Menguc, 2005; Yang and Li, 2011).

The literature has already analyzed several contingent factors such as dynamism, competitiveness and appropriability regime (Jansen et al., 2006; Yang and Li, 2011). In these works, some of the arguments used refer explicitly to how the changes in technologies and fluctuations in demand jointly affect firms that belong to the same industry (Jansen et al., 2006; Yamakawa et al., 2011). In other words, these arguments describe the evolution of the 
industry and, more specifically, the aggregate effect of the pace of technology evolution and the pace of market evolution, which previous literature considers as two important categories that have been used to describe the environment (Dess and Beard, 1984; Sharfman and Dean, 1991).

The evolution of the industry has been studied within the context of exploration and exploitation strategies in aggregate terms. The main assumption of this stream of research is to consider that the effect of this evolution is equivalent to the sum of its different components (Jansen et al., 2006; Yamakawa et al., 2011; Yang and Li, 2011). However, technology and strategic management literatures have already acknowledged that the pace of market evolution and the pace of technology evolution are two distinct factors that introduce an explicitly dynamic dimension to analyze the evolution of the industry and that their dynamic may differ (Suárez and Lanzolla, 2007). Therefore, it is surprising that the literature on exploration and exploitation has mostly analyzed the evolution of the industry in a broad sense (Lumpkin and Dess, 2001; Jansen et al., 2006; Yang and Li, 2011), neglecting the different influences that its components may have.

In this paper, we elaborate on this idea and we will break down the evolution of the industry into its underlying constituents, i.e. the pace of technology evolution and the pace of market evolution (Suárez and Lanzolla, 2007), to analyze their moderating influence on the relationships between exploration, exploitation and innovation performance. For the purposes of this paper, we define industry evolution as the perceived continuity of changes in an industry (Zahra, 1996). We build on technology and strategic management literatures that have considered the evolution of industry as a multidimensional concept (McCarthy, Lawrence, Wixted and Gordon, 2010). More precisely, we advocate that the paces of market and technology evolution have different impacts (Katz and Shapiro, 1992; Suárez and Lanzolla, 2007) and that they deserve to be studied separately. Our contention is that the pace 
of market evolution strengthens the relationships between exploration and exploitation and innovation performance, while the pace of technology evolution boosts the innovation performance associated with exploration strategies, but inhibits that of exploitation strategies.

We test our hypotheses within the Technological Innovation Panel database (PITEC), which contains information about the innovative activity of Spanish companies. This database is particularly useful for the purposes of our work at least for two reasons. First, it provides information about companies belonging to different sectors. This means that there is sufficient variability in the two components of the evolution of the industry for our purposes. Second, it allows us to identify exploration and exploitation strategies over a time frame of five years.

Our contribution to the literature is twofold. First, it extends our knowledge on the impact of the evolution of the industry on exploration and exploitation strategies by considering two components, market and technology evolution. To the best of our knowledge, there are no previous attempts, either theoretical or empirical, to analyze the industry evolution in a more granular way. Given the opposite influences that the paces of market and technology evolution may have, some of the previous findings in the literature could be threatened (Jansen et al., 2006; Wang and Li, 2008; Yang and Li, 2011). Second, we offer a muchneeded longitudinal perspective in the analysis of the impact of environmental factors (Auh and Menguc, 2005). The literature on exploration and exploitation has conceptualized and measured environmental conditions as static variables (Jansen et al., 2006; Yang and Li, 2011) although they clearly have a dynamic nature (McCarthy, Lawrence, Wixted and Gordon, 2010). Several studies postulate that any structural change that modifies the conditions of competition does not occur at a particular moment in time, but encompasses a longer period (Agarwal, Sarkar and Echambadi, 2002). Based on this contention, the consideration of environmental attributes as static prevents us from perceiving the full extent 
of their effects. Consequently, the inclusion of the time factor allows us to address the impact of the two dimensions more rigorously.

\section{THEORETICAL BACKGROUND}

\subsection{Exploration, exploitation and innovation performance}

The concepts of exploration and exploitation are generally used to describe activities that are essential for organizations in sustaining and ensuring their competitive advantages (Isobe, Makino and Montgomery, 2004 Sidhu, Commandeur and Volberda, 2007). In his seminal paper, March (1991) describes exploitation and exploration as two different forms of learning activities. Exploration strategies are associated with search, discovery, experimentation and development of new knowledge, while exploitation strategies involve activities that seek the refinement and extension of existing knowledge and are associated with convergent thinking (Levinthal and March, 1993).

The obvious differences between exploration and exploitation strategies have led a stream of the literature to consider them as not only different but also incompatible (March, 1991; Uotila et al., 2009). One of the arguments that support this idea is that exploration and exploitation compete for scarce resources. Therefore, more resources devoted to one of them will lead to fewer resources left for the other (Danneels and Sethi, 2011). Moreover, the mindsets and organizational routines needed for exploration could be radically different from those needed for exploitation. That fact makes, as suggested by this stream of research, the simultaneous pursuit of both impossible (March, 1991). Based on these arguments, exploration and exploitation strategies could be seen as two ends of a continuum and, therefore, mutually exclusive (Rosenkopf and McGrath, 2011).

Another line of research on which this paper is built, has questioned some of these assumptions, arguing that exploration and exploitation strategies are independent activities, basically because they are not necessarily in fundamental competition (Gupta, Smith and 
Shalley, 2006). In the same vein, some researchers have even understood that exploration and exploitation strategies can be mutually supportive, each helping to leverage the effect of the other. Cao et al., (2009), among others, have argued that, since exploitation investments could allow firms to have a deeper understanding of the existing knowledge, they could enhance the firm's ability to effectively explore new knowledge and to develop resources that support the introduction of new products and services. Similarly, exploration investments could help firms to exploit successfully, since internalizing more external knowledge could allow exploitation to take place on a greater scale (Gupta et al. 2006). Therefore, as exploration and exploitation could be achieved simultaneously, this line of research takes them to be orthogonal to each other (Rothaermel, 2001; Beckman, Haunschild, and Phillips, 2004).

Despite the different points of view of researchers analyzing exploration and exploitation strategies, it is widely accepted that they are clearly different types of innovation strategies (Faems et al., 2005), a fact that has lead scholars to analyze their distinct impact on innovation performance (Rothaermel and Deeds, 2004; Jansen et al., 2006). At first, researchers focused on whether the development of each of these strategies was related to innovation performance (Faems et al., 2005). These studies obtained somewhat conflicting results (Lavie, Stettner and Tushman, 2010). Whereas most researchers find positive innovation performance effects for exploration (Yalcinkaya, Calantone and Griffith, 2007) and exploitation strategies (Faems et al., 2005), others find no relationship (Amason, Shrader and Tompson, 2006) or even a negative association (Yalcinkaya et al., 2007). These nonconclusive results could be related to the drawbacks of each strategy. In this vein, researchers, such as Rosenkopf and Nerkar (2001), have shown that too much exploration, i.e., overexploration, leads organizations to focus on long-term performance, renouncing shortterm outcomes. They also show that too much exploitation, i.e., overexploitation, generates 
rigidity problems because it prevents organizations from being able to break out of their technological trajectory and, thereby, to compete in the long-term.

Another possible reason for these conflicting results is the risks that each strategy entails. Scholars like Auh and Menguc (2005) have argued that, given that exploitation strategies aim at creating and commercializing improved products and services (Benner and Tushman, 2003), innovating firms are familiar with innovation outcomes which involve lower risk. Furthermore, because organizations developing exploitation strategies often obtain high synergies with the knowledge they already have (Mueller, Rosenbusch and Bausch, 2013), economies of scale and scope will increase innovation performance (Auh and Menguc, 2005). Moreover, and given that these organizations apply their prior knowledge, they can also benefit from learning curve effects, leading to a positive effect on innovation performance (Morgan and Berthon, 2008; Mueller et al., 2013). However, because these low-risk strategies do not allow the creation of products with a high degree of novelty, many firms may develop similar products and, hence, not reap the benefits that they expect from their innovation processes, which could even result in a negative impact (Mueller et al., 2013).

Meanwhile, exploration strategies are considered to be high-risk because their implementation requires a large amount of resources and, to be successful, firms must be able to allocate these resources to high-risk projects whose outcomes are unpredictable (Rosenkopf and Nerkar, 2001).

\subsection{Exploration, exploitation and the evolution of industry}

In the context of exploration and exploitation strategies, researchers have started to address the importance of the opportunities and threats that come from the environment (Wang and Li, 2008; Yamakawa et al., 2011). Since they are considered learning activities, a stream of the literature has analyzed whether exploration and exploitation strategies allows firms to adequately adapt and reconfigure their organizational skills to match changing 
environments (Rosenkopf and Nerkar, 2001; O'Reilly and Tushman, 2008). Most researchers have concluded that it is the ability of a firm to simultaneously explore and exploit, named ambidexterity, what really allows firms to adapt to their environment over time (O'Reilly and Tushman, 2008). Both strategies, exploration and exploitation, have been acknowledged to be specific organizational processes that create value for firms. In keeping with this idea, Das (2006) and Hendry and Brown (2006) have argued that, since to explore and to exploit at the same time allows firms to adapt to new requirements over time, they could be conceived of as a dynamic process of strategic renewal. In the same vein, Crossan, Lane and White (1999) and Fischer, Gebauer, Gregory, Ren and Fleisch (2010) have conceptualized exploration and exploitation strategies as dynamic capabilities, as they have the capacity to formulate a response to a need or an opportunity for change.

In addition to being considered dynamic capabilities that allow firms to adapt to their environment over time, exploration and exploitation strategies have been studied under the effect of some dimensions of the firm's environment (Jansen et al., 2006; Yang and Li, 2011). Among the different dimensions that characterize an environment (Dess and Beard, 1984), a well-researched one is the evolution of industry (Lumpkin and Dess, 2001). Scholars have shown interest in this factor since industry evolution reflects the situation of an industry and the conditions that the environment offers. In this way, industry evolution will affect the impact that exploration and exploitation strategies have on innovation performance. As a starting point, scholars have acknowledged that an industry evolves through different phases that make up the industry lifecycle (Abernathy and Utterback, 1978). Specifically, three stages of industry evolution are commonly recognized: an early exploratory stage, an intermediate development stage and a mature stage (Utterback, 1994).

Based on this, researchers have argued that the industry life cycle could affect firms' emphasis on exploration and exploitation strategies. Particularly, there is empirical support 
for a higher success rate of exploration firms in early exploratory stage industries. In these industries, demand is constantly growing, offering a wide variety of technological and market opportunities (Rawski, 1994). For this reason, the firms that benefit most from this context are those that are inclined to anticipate future demand through technological leadership (Lumpkin and Dess, 2001). This is precisely what exploration strategies, based on the constant introduction of completely new products and services, offer. Therefore, in such a context, firms more oriented to exploration will be more strongly associated with high performance (Lumpkin and Dess, 2001). In contrast, in mature industries, characterized by slow growth, firms that tend to focus on strategies related to complementarity and mutual interdependence, such as exploitation strategies, may succeed. When firms are under little pressure to take risks through exploring new contexts and developing new ideas (Rajagopalan and Deepaic, 1996), exploiting existing resources could allow them to protect their gains and boost their innovation performance (Lumpkin and Dess, 2001).

Nevertheless, scholars have not only demonstrated that the phases of the industry life cycle affect the impact of exploration and exploitation on innovation performance but that the way in which these phases occur depends on some dimensions of industry evolution, such as the variation in technological design alternatives, investments in different kinds of innovation, market structure and the basis of competition (Cusumano, Kahl and Suarez, 2015).

In this paper, we draw on industry evolution and on its multidimensional character. We decompose industry evolution into two components that are recognized by previous literature as factors that clearly introduce an explicitly dynamic dimension to analyze the evolution of the industry (McCarthy et al. 2010; Suárez and Lanzolla, 2007), namely, the pace of technology evolution and the pace of market evolution. We propose that they evolve independently with respect to the relationships between exploration and exploitation strategies and innovation performance. Our starting point is that each of these dimensions 
could have a different impact on the relationships stated above. To our knowledge, there is no theoretical or empirical work that analyzes industry evolution by considering its different components (Wang and Li, 2008; Yang and Li, 2011; Uotila et al, 2009).

\section{HYPOTHESES}

\subsection{The pace of technology evolution}

One element that affects firms' behavior is the rate at which technology evolves in the environment in which they operate (Tushman and Anderson, 1986). Traditionally, the literature has used this factor to explain the speed at which the products and services that have been introduced into an industry become technologically obsolete (Zahra, 1996; Zahra and Bogner, 1999). Following Zahra (1996), we understand the pace of technology evolution as the level of change that technology undergoes in a specific period of time.

A rapid pace of technology evolution means that existing products and services cannot satisfy market needs (Tushman and Anderson, 1986; Zahra, 1996). This is because technology evolution has created new technology requirements, a fact that prompts organizations to develop new products and services to meet this lack (Zahra, 1996; Wind and Mahajan, 1997; Sorensen and Stuart, 2000). However, firms are not yet aware of market preferences. Given this uncertainty, firms have to turn to experimentation if they want to introduce a dominant technological standard (Zahra, 1996; Zahra and Bogner, 1999). The more numerous the product design alternatives resulting from this process, the more likely these firms will satisfy the unmet needs (Zahra, 1996; Fleming and Sorenson, 2001).

Therefore, it seems that the implementation of strategies whose dynamic has its origin in trial and error and which are based on the constant development of innovations with a high degree of novelty, could be an appropriate response to a context of rapid technology evolution. This is precisely the nature of exploration strategies, whose starting point is the search for information outside the boundaries of the organization (Atuahene-Gima, 2005). As 
a result, firms implementing exploration strategies obtain a wider-ranging knowledge that fosters the constant introduction of new products and services (Benner and Tushman, 2003; Atuahene-Gima, 2005). Because an environment characterized by rapid technology evolution allows the introduction of multiple product designs (Zahra, 1996), firms developing exploration strategies can more easily place in the market the innovations that they have introduced. Accordingly, firms' investments associated with novelty will be more useful (Lumpkin and Dess, 2001).

In addition, firms developing exploration strategies could more easily capture returns from innovations because, as technological requirements are renewed quickly, competitors will not be able to imitate the innovations introduced (Zahra, 1996; Zahra and Bogner, 1999). Therefore, the organizations that have created the innovations may acquire an advantage over their competitors, a fact that could be particularly beneficial for organizations that develop exploration strategies because they have invested abundant resources and assumed a high risk (Atuahene-Gima, 2005; Debenham and Wilkinson, 2006). Consequently, organizations developing exploration strategies may have above-normal returns (Jansen et al., 2006).

Therefore, a context like this could enhance the effect of exploration strategies on innovation performance. In accordance with this, we propose our hypothesis as follows:

HYPOTHESIS 1a: Rapid technology evolution positively moderates the relationship between exploration and innovation performance.

On the contrary, an environment characterized by rapid technology evolution might not be equally favorable for organizations that develop exploitation strategies. Firstly, because the satisfaction of the needs of emerging markets seems more likely through the constant introduction of innovations with a high degree of novelty (Jansen et al, 2006; Kim and Rhee, 2009). Nevertheless, as is well known, the dynamic of the organizations that develop exploitation strategies does not support this type of innovative behavior (Benner and 
Tushman, 2003; Atuahene-Gima, 2005). As a result, organizations that develop exploitation strategies could find it difficult to place the innovations that they have introduced. Consequently, the investments in innovations they have made may not prove as profitable as they expected.

Secondly, rapid technology evolution could be particularly unfavorable for firms whose technological trajectory is maintained over time (Jansen et al., 2006). This is because their new creations, being very close to those developed previously, become obsolete even faster (Zahra, 1996). Given that organizations that develop exploitation strategies follow this dynamic, they are especially vulnerable in this context (Zahra and Bogner 1999).

With these arguments in mind, it seems logical to consider that an environment characterized by rapid technology evolution is not optimal for the development of exploitation strategies. Based on all the above arguments, we propose the following hypothesis:

HYPOTHESIS 1b: Rapid technology evolution negatively moderates the relationship between exploitation and innovation performance.

\subsection{The pace of market evolution}

The pace of market evolution is another environmental attribute that may affect organizations' pattern (Raisch and Hotz, 2008). The market evolution of an industry is usually characterized by an initial period of slow growth. This phase is followed by an intense increase and a later phase of market maturity and decline (Suárez and Lanzolla, 2007). Thus, rapid market evolution implies that fluctuations in product demand are high while, if the market grows slowly, the demand will follow the same path (Yamakawa et al., 2011).

If the market is evolving rapidly, the continuous fluctuations in product demand could have two fundamental implications. First, the risk involved in carrying out innovation investments could be minimized (Lumpkin and Dess, 2001). In this type of context, all products and services developed will have a space, because the excess demand will 
accommodate them (Klepper, 1997). This could be especially beneficial for organizations that develop exploration strategies, for which the loss of their investments, given its magnitude, could seriously undermine their innovation performance (Lavie et al., 2010). Exploration firms continuously experiment with new knowledge (Zahra, 1996), a fact that explains why their investment in innovation is high (Zahra and Bogner, 1999; Atuahene-Gima, 2005). However, this means that they have to assume a high level of risk, generally considered as one of the impediments to their development (Lavie et al, 2010; Mueller et al, 2013). If this risk could be reduced by the continuous growth of the demand, these firms will be able to take advantage of the investments they have made.

Second, the competitive conditions of the industry could be modified precisely by this continuous growth of the demand that makes the market more attractive (Lumpkin and Dess, 2001; Yamakawa et al., 2011). Thus, more firms could be interested in entering the market (Raisch and Hotz, 2008). However, due to the fluctuations in product demand that characterizes the industry, the firms in this industry will have sufficient resources and the competition will exert less pressure (Lumpkin and Dess, 2001). Therefore, these organizations are not obliged to set low prices to compete (Jansen et al., 2006). This could be especially beneficial for organizations that develop exploration strategies because their implementation involves high costs to be recovered (Lavie et al, 2010). As competition gives a greater clearance in the pricing (Jansen et al., 2006), organizations that develop exploration strategies could recover their investment in innovation by setting a price in accordance with the characteristics of the product they offer.

In addition, and because of the possibility of charging higher prices, the competition will focus on offering products and services that better satisfy the new requirements (Schmidt and Calantone, 1998). In this context, characterized by continuous fluctuations in product demand that has to be satisfy, it seems logical that organizations which anticipate the future demand 
will be able to satisfy customer needs better than the rest. As is well known, exploration strategies are based precisely on the discovery of new knowledge and resources that enable companies to move away from the path previously followed (Atuahene-Gima, 2005). Thus we might think that organizations that develop exploration strategies will be trained to meet the new requirements that a rapid pace of market evolution has created.

For all the reasons above, we consider that rapid market evolution is attractive for the development of exploration strategies. Consequently, the innovation performance that results from these strategies could experience a boost. Accordingly, the following hypothesis is formulated:

HYPOTHESIS 2a: Rapid market evolution positively moderates the relationship between exploration and innovation performance.

Likewise, rapid market evolution could be beneficial for the development of exploitation strategies. This is because it is an environment characterized by continuous fluctuations in product demand, a fact that could imply that there will be very different needs to be satisfied (Lumpkin and Dess, 2001). This may mean that even the introduction of innovations that only improve the existing products and services will be accommodated (Lumpkin and Dess, 2001; Raisch and Hotz, 2008). As a result, organizations that develop exploitation strategies may find a place in an environment characterized by rapid market growth and be able to increase their cash flow (Lumpkin and Dess, 2001), taking advantage of their investments in innovation. In other words, in this type of context, where it is optimal not to do better than the competitors, but to do what is best for the company (Armstrong and Collopy, 1996), the development of exploitation strategies could succeed.

Moreover, and given the possibility of setting higher prices, organizations developing exploitation strategies will be able to obtain a substantial margin. Because of the presence of scale economies, firms developing exploitation strategies can concentrate on cost reduction 
and get the most out of their existing resources (Porter, 1980) without making large investments (Lavie et al., 2010) and they do not have to assume a high risk. Hence, although their prices are similar to those of their competitors, they will be able to capture important benefits because the costs they will have to recover are not as high as those made by organizations that incorporate a higher level of risk.

In sum, it seems logical that the conditions of an environment characterized by rapid market evolution are appropriate for the development of exploitation strategies. Given that the high demand and the competition conditions allow organizations that focus on exploitation strategies to make above-normal profits, we might think that rapid market evolution potentiates the effect of the implementation of these strategies on innovation performance. As a consequence of all the arguments set out above, the following hypothesis is proposed:

HYPOTHESIS 2b: Rapid market evolution positively moderates the relationship between exploitation and innovation performance.

\section{DATA AND METHODOLOGY}

\subsection{Sample}

To test our hypotheses we draw on a panel data set of innovating firms, the Technological Innovation Panel database (PITEC). This database provides annual information about the innovation activities of a large sample of Spanish manufacturing and service firms from 2003 to 2012. The data are collected by the National Institute of Statistics (INE) with the support of the Spanish Foundation for Science and Technology (FECYT) and the Spanish Foundation for Technological Innovation (COTEC). PITEC is based on the Community Innovation Survey (CIS) framework, which is a valid tool for studying innovation and is one of the most frequently used datasets in this context. ${ }^{1}$ Finally, it is important to highlight that these data

\footnotetext{
${ }^{1}$ The dataset, the questionnaire and the description of each variable is available at the website: http://icono.fecyt.es/PITEC/Paginas/por que.aspx In order to avoid the identification of the firms, some variables are "anonymized". López (2011) shows that the expected biases due to this anonymization are small through the comparison of regressions that use original and harmonized data alternatively.
} 
have been previously used for several purposes (see for instance Vega Jurado, Gutierrez Gracia and Fernandez de Lucio, 2009; De Marchi, 2012; Barge-Gil and López, 2014; D'Este, Marzucchi and Rentocchini, 2017 or Pellegrino, 2018).

PITEC is particularly appropriate for the purposes of this work. First, it provides information about the innovation objectives of each firm. With this information in mind, and following the logic of previous papers (see, for example He and Wong, 2004 and Archibugi, Filippetti and Frenz, 2013), we are able to characterize exploration and exploitation strategies. Second, PITEC contains information for firms operating in very different industrial settings. This means that we have sufficient variability in both the paces of market evolution and technology evolution for our purposes. Finally, and as argued before, the dataset, based on survey waves, has a longitudinal dimension, spanning information from to 2003 to 2012. Although the information is provided from 2003 on, due to the availability of the information we need ${ }^{2}$, we construct a panel dataset by using the time frame 2008-2012, aggregating information from five PITEC annual survey waves. In addition, since we are analyzing the differences in the innovation performance of the organizations that develop exploration and exploitation strategies, our analysis is restricted to firms engaging in innovative activities (He and Wong, 2004; Laursen and Salter, 2006). ${ }^{3}$ After excluding noninnovation firms, we restricted our sample to manufacturing and service firms. We also exclude firms with no information on the main variables, those that have suffered problems associated with mergers and acquisitions and those that are public or newly created (Vega Jurado, Gutierrez Gracia and Fernandez de Lucio, 2009). Finally, to make sure that our results are not driven by the presence of outliers, we have dealt with their identification.

\footnotetext{
${ }^{2}$ For building the exploration and exploitation variables, information is only available from 2008 , which limits the final observation window to the period 2008-2012.

${ }^{3}$ Innovators are firms that, in any period, have developed product innovations or process innovations or have started an innovative activity and it is still ongoing or has been abandoned.
} 
Thirteen outliers have been identified and have been excluded from the sample. This means that we have a sample of 23,015 observations.

Tables 1 and 2 offer descriptive statistics of our final sample by industry (manufacturing vs service), technological level (high vs low) ${ }^{4}$ and size. ${ }^{5}$

Insert Table 1 Here

\subsection{Variables}

\section{Dependent variable}

In order to measure innovation performance, we have used the fraction of the firm's total turnover in year $\mathrm{t}$ related to the firm's new products introduced during the years $\mathrm{t}-2, \mathrm{t}-1$ and $\mathrm{t}$. We understood the firm's new products in line with the Oslo Manual, that is, as the sum of the products that the firm has introduced and that have been considered "new to the market" and the products that have been considered only "new to the firm".

This measure of innovation performance has been previously used for very similar purposes (see, for example, Laursen and Salter, 2006; Bauer and Leker, 2013) and is considered a good proxy not only for a firm's ability to introduce new products but also for its commercial success (Woerter and Roper, 2008; Tsai, 2009).

\section{Independent variables}

Following previous papers (see, for example, He and Wong, 2004 and Archibugi, Filippetti and Frenz, 2013), we measure exploration and exploitation through ten Likert-scale items to analyze to what extent firms dedicate their attention and resources to various innovation

\footnotetext{
${ }^{4}$ We have used the OECD (2005)'s classification of industries to create the high-tech and low-tech groups. Additional information is available at the website: http://www.ine.es/daco/daco43/notaiat.pdf

${ }^{5}$ Classification carried out in accordance with the criteria established by the European Commission Regulation (CE) $\mathrm{N}^{\circ} 800 / 2008$ of 6 August 2008 (DOUE L214/3 of 9 of August, 2008), which defines the requirements for three categories of companies: microenterprise, comprising those which employ fewer than 10 workers, small business, which includes those which employ 10 to 49 workers and medium enterprises, those that employ between 50 and 249 workers.
} 
activities with explorative and exploitative objectives. The PITEC questionnaire includes some questions that determine if the company has focused, in general terms, on experimenting with new alternatives or on refining and extending existing competencies and technologies. These questions, which are used to construct our independent variables, refer to a three-year period ${ }^{6}$ and investigate firms' objectives ex-ante. We used firms' objectives exante as we consider that the strategic intentions of the organizations determine whether exploration and exploitation are developed (He and Wong, 2004; Archibugi et al., 2013).

Based on the answers that firms gave to these questions, contained in ten items, we have constructed our exploration and exploitation variables. Factor analysis (see Table 3 ) is used to reduce the ten items to two factors, exploration and exploitation strategies, with acceptable Cronbach alphas $(0.886$ and 0.896 , respectively). As we consider exploration and exploitation as independent strategies, an orthogonal varimax rotation was performed. As a result, we obtained two factors that are thought to be independent.

Insert Table 3 Here

\section{Moderating variables}

The pace of technology evolution and the pace of market evolution are the moderating variables in this paper. In line with Uotila et al. (2009), we measure technology evolution through the intensity of R\&D in the industry, calculated as the industry's total R\&D expenses divided by total number of employees.

Consistent with previous studies (Yamakawa et al., 2011) the pace of market evolution is measured through industry sales growth, which reflects the opportunities in the environment. To measure industry sales growth, we must obtain industry sales, calculated as the sum of the

\footnotetext{
${ }^{6}$ Since some variables are constructed using questions that refer to a three-year period, there could be an overlapping effect. However, Raymond, Mohnen, Palm and Van Der Loeff (2010) and Clausen and Pohjola (2013) found that the effect of such an overlap is a minor issue.
} 
sales of the firms in the same industry. Industry sales growth is obtained from the ratio of industry sales in year $\mathrm{t}$ and industry sales in year $\mathrm{t}-1$.

Both variables have been constructed using the information that PITEC provides about industry total $R \& D$ expenses, total industry sales in year $t$ and total industry sales in $t-1$, that is, aggregating the individual data of the firms in the sample.

\section{Control variables}

In addition to the independent variables and moderators, we control for a variety of variables that are classified into two groups: firm and industry variables.

Several papers suggest that there is a positive relationship between firm size and innovation performance (Cassiman and Veugelers, 2006). Following Yang and Li (2011), we have measured firm size as the number of employees. It is also necessary to control for the innovative intensity of the firms, because if it is high, the results from innovation strategies will increase (Uotila et al., 2009). Following the literature that measures innovative intensity through the ratio of total firm $R \& D$ and firm size (Laursen and Salter, 2006), we use this measure to proxy the variable. Furthermore, we need to control whether the firm operates in an international context. Several papers have pointed out that firms that operate internationally are more innovative (Galende and Suarez, 1999; Cassiman and Veugelers, 2006). We proxy this variable through the ratio between exports and sales (Nieto and Santamaría, 2007). As in previous papers, we expect a positive relationship between innovation performance and export activity. Researchers also think that the participation of foreign capital affects the propensity of organizations to innovate. This is because their ownership structure can facilitate a more effective knowledge transfer (Love and Roper, 2001; Desai, Foley and Hines, 2004). Some investigations have measured this variable through a dummy variable that takes the value 1 if the firm has foreign capital participation and 0 otherwise (Sadowski and Sadowski-Rasters, 2006) and this is how our paper is going to 
measure it. In addition, and based on Rothaermel and Alexandre (2009) and Yang and Li (2011), we included exploration and exploitation strategies in its quadratic form as control variables, in order to control the impact of overexploration and overexploitation on innovation performance.

The innovative activity of organizations is, in turn, affected by factors related to the sector to which the firm belongs (Miotti and Sachwald, 2003; Auh and Menguc, 2005). To measure this effect, this work has included a dummy variable that classifies the firms under study by sector, in accordance with the CNAE 2009 code. In addition, we also account for time effects by introducing appropriate dummies, which allow us to treat the overlapping effect of PITEC (Clausen and Pohjola, 2013).

\subsection{Descriptive Statistics}

Table 4 shows the descriptive statistics of the sample as well as the correlation matrix. Our sample consists of a total of 23,015 observations that are used in the model. The mean of the dependent variable is 0.202 , which indicates that an average of $20 \%$ of the turnover of the firms comes from the introduction of innovations new to the firm or new to the market.

With respect to the independent variables, Table 4 shows the average scores that firms have given to the objectives that define exploration and the average scores that they have given to the exploitation innovation objectives.

Finally, the correlation matrix shows that, generally, the variables have low correlations between them. This means that there will be no problems of multicollinearity. However, variance inflation factors (VIFs) were computed to assess the severity of multicollinearity. The average VIF value is 1.27 , which is well below the cut-off point of 10 (Chatterjee, Hadi, and Price, 2000), a fact that means that we do not experience problems of multicollinearity if we include these variables in the same regression. 
In addition, and since our moderator and industry variables are measured at the same NACE aggregation level, we have calculated the correlations between them, obtaining evidence that we have no problems of multicollinearity if we include them in the same regression.

Insert Table 4 Here

\subsection{Methodology}

We study the impact of the paces of market and technology evolution on the relationships between exploration and exploitation strategies and innovation performance. Formally, these relationships are expressed in Model 1, where, following previous literature (He and Wong, 2004), both the independent and the moderating variables have been lagged by one period.

\section{Model 1.}

Innovation performance $_{t}=\beta_{0}+\beta_{1} \times$ Exploration $_{t-1}+\beta_{2} \times$ Exploitation $_{t-1}+\beta_{3} \times$ Paceof techevolution $_{t-1}+$ $+\beta_{4} \times$ Paceof techevolution $_{t-1} \times$ Exploration $_{t-1}+\beta_{5} \times$ Paceof techevolution $_{t-1} \times$ Exploitation $_{t-1}+$ $+\beta_{6} x$ Paceof markevolution $_{t-1}+\beta_{7} \times$ Pace of markevolution $_{t-1} \times$ Exploration $_{t-1}+$ $+\beta_{8} \times$ Paceof markevolution $_{t-1} \times$ Exploitation $_{t-1}+\beta_{9} \times$ Control variables $_{t-1}+\varepsilon$

For the analysis, we use random-effects panel Tobit model (Grimpe and Kaiser, 2010). Since the innovation performance variable is a doubled censored variable, representing the percentage of sales of new products that, by definition, ranges between 0 and 100 , the applicable methodology is a Tobit regression (Greene, 2000). In addition, it should be noted that, since the literature has found that variables that reflect the innovation performance of organizations may present problems of asymmetry and deviation from normality (Filippucci, Drudi and Papolia, 1996; Laursen and Salter, 2006), we have calculated the logarithmic transformation of the dependent variable. Following previous literature (He and Wong, 2004), 
the independent and moderating variables have been centered on their means to simplify the interpretation of the coefficients (Aiken and West, 1991; Yang and Li, 2011).

\section{RESULTS}

Table 5 shows Tobit estimates for the relationship between exploration and exploitation strategies and innovation performance. ${ }^{7}$

We have run three nested models. Model 1 is the based model that only includes the control variables. Model 2 introduces the direct effects of exploration and exploitation and their quadratic form. Finally, Model 3, the full model, includes the pace of technology and the pace of market evolution and their interactions with exploration and exploitation. It is important to note that, if we compare the models through the Wald test -shown at the end of the table-, the complete model has the greatest explanatory power.

In Model 1, we observe that the development of international activities has a positive and significant effect on innovation performance. Similarly, higher innovation intensity is positively and significantly related to a superior innovation performance. This is in line with Nieto and Santamaría (2007). Firm size also has a positive and a significant influence on innovation performance. This is consistent with previous findings that maintain that innovation strategies can be affected by size through economies of scale and scope (Cassiman and Veugelers, 2006). Our results show that the participation of foreign capital has no significant effect on innovation performance. The dummy variables capturing time-specific influences and the effect of the industry are globally significant. With regard to our control variables, it is important to note that the sign and significance of all of them are highly stable in Models 2 and 3, but for size that loses its significance in the full model.

In Model 2, we observe that the development of exploration and exploitation strategies is positive and significantly related to innovation performance. Interestingly, our results reveal

\footnotetext{
${ }^{7}$ As can be observed, our number of observations declines from the 23,015 showed in the descriptive statistics to 15,286 , since both the independent and the moderating variables have been lagged one period.
} 
that there is a negative and significant relationship between the quadratic version of the exploration variable and innovation performance $(\beta=-0.0240 ; p<0.001)$. This means that the relationship between exploration and innovation performance has an inverted U-shaped. In other words, it seems that low and high levels of exploration have a negative impact on innovation performance. This finding is consistent with Yang and Li (2011), who postulated a negative relationship between the development of low and high levels of exploration and innovation performance. On the contrary, our data shows a positive and significant relationship between the quadratic version of exploitation and our dependent variable $(\beta=$ $0.0116 ; \mathrm{p}<0.001)$.

Model 3, the full model, incorporates the pace of technology ${ }^{8}$ and the pace of market evolution variables together with their interactions with exploration and exploitation strategies. The data shows that the pace of technology evolution positively moderates the relationship between exploration and innovation performance $(\beta=0.00173 ; p<0.05)$, which is consistent with Hypothesis 1a. This means that exploration processes seems more appropriate in a context characterized by rapid technology evolution. On the contrary, our results show that the pace of technology evolution has no significant effect on the relationship between exploitation and innovation performance. This does not support Hypothesis 1b. As for the pace of market evolution, our results show that this variable positively moderates the relationship between exploration and innovation performance $(\beta=0.0454 ; p<0.10)$, which supports Hypothesis 2a. We also observe that the pace of market evolution has a positive and a significant effect on the relationship between exploitation and innovation performance $(\beta=$ 0.0356; $\mathrm{p}<0.10$ ), which is in line with Hypothesis $2 \mathrm{~b}$.

Insert Table 5 Here

\footnotetext{
${ }^{8}$ We carried out the same analysis using total industry sales and the resulting conclusions were unchanged.
} 


\subsection{Overexploration, overexploitation and industry evolution}

In this part of the paper, we will further investigate the relationships between exploration and exploitation and innovation performance, analyzing their curvilinear effects and how technology and market evolution moderates these effects. To do so, we depart from one of the concerns of the literature on exploration and exploitation, which is related to the "dark side" of these strategies (Rothaermel and Alexandre, 2009). Already in 1991, March warned about the risk of engaging in high levels of exploration and exploitation, in phenomena that the literature referred to as overexploration and overexploitation (Yang and Li, 2011).

On the one hand, a high level of exploration facilitates organizations in the accumulation of new knowledge, but the integration of this knowledge involves a high risk that can adversely affect innovation performance (Rothaermel and Alexandre, 2009). On the other hand, a high level of exploitation hampers firms in taking new directions and entering different market domains. This drives companies developing exploitation strategies to focus on secondary alternatives, becoming only viable, in terms on innovation performance, in the short-term (Yang and Li, 2011). Based on these arguments, scholars have argued that the relationships between exploration and exploitation strategies and innovation performance may show a non-linear effect (Katila and Ahuja, 2002; Rothaermel and Alexandre, 2009; Yang and $\mathrm{Li}, 2011)$.

In keeping with this idea, extant literature has started to address this issue. While some investigations have found that these relationships acquire the shape of an inverted $U$ (Rothaermel and Alexandre, 2009), other papers have provided empirical evidence in the opposite direction (Atuahene-Gima and Murray, 2007), that is, that exploration and exploitation strategies and innovation performance may present a U-shaped relationship. Moreover, some researchers have even failed obtaining statistically significant results of these relationships (Katila and Ahuja, 2002). In the absence of consensus around this, some 
scholars have pointed to the need for analyzing overexploration and overexploitation from a contingent perspective (Yang and $\mathrm{Li}, 2011$ ). The underlying rationale is that the impact on innovation performance of the resources invested in each strategy may vary depending on other factors, such as the context in which the firm is operating (Jansen et al., 2006).

With the aim of offering some insights into the curvilinear effects of exploration and exploitation strategies on innovation performance, in this part of the paper, we illustrate how medium, low and high levels of technology and market evolution influence overexploration and overexploitation. These three levels are represented by the mean values of technology and market evolution, two standard deviations below the mean values, and two standard deviations above the mean values, respectively. Specifically, we focus on how the inflection point changes its position depending on the levels of technology and market evolution (Haans, Pieters and He, 2016). By doing this, we will be able to analyze how the environmental factors, specifically the evolution of the industry, allow us to better understand the shapes of the relationships between overexploration, overexploitation and innovation performance. To make this possible, we define three ${ }^{9}$ different scenarios (Oriani and Sobrero, 2008), taking as reference the possible combinations that we could obtain between overexploration and overexploitation, and technology and market evolution. For each of the three scenarios, we construct one graph, which consists in three curves, one for each level of technology and market evolution. In order to further corroborate the movement that the tipping point undergoes, we include Table 6, which specifies the tipping point of each of the three curves of the three different scenarios.

\section{Overexploration and technology evolution}

As can be seen in Graph 1, there is an inverted U-shaped relationship between exploration and innovation performance, regardless of the level of technology evolution. This

\footnotetext{
${ }^{9}$ As our results indicate that the interaction effect between exploitation strategies and technology evolution has no significant effect (see Table 5), we have not included the graph.
} 
is in line with previous findings (Uotila et al., 2009; Yang and Li, 2011) that have demonstrated that there is a negative relationship between low and high levels of exploration and innovation performance. However, although the shape of the three curves is similar, it seems that, as the level of technology evolution increases, the tipping point, in which the effect of exploration turns from increasing to decreasing, occurs for higher values of exploration. This means that the negative effects that overexploration generates emerge later when the evolution of technology is increasing its pace. A possible explanation for this phenomenon could be found in the fit between exploration strategies and an environment characterized by a high pace of technology evolution. In such an environment, in which the technological demands change continually (Yang and Li, 2011), firms developing exploration strategies, whose dynamic is based on the experimentation (Atuahene-Gima, 2005), could better place the numerous innovations that they have introduced. In contrast, in a context in which the technology evolves at a low pace, firms developing exploration strategies could encounter difficulties. In keeping with this idea, one can expect that exploration firms operating in environments characterized by a high pace of technology evolution will take more out of their investments. Therefore, in this context, the costs associated with overexploration will appear for higher levels of exploration. Table 6 corroborates that fact, as, for high levels of technology evolution, the tipping point is 2.031 , for medium levels, it is 1.466 , and for low levels, it is 0.901 .

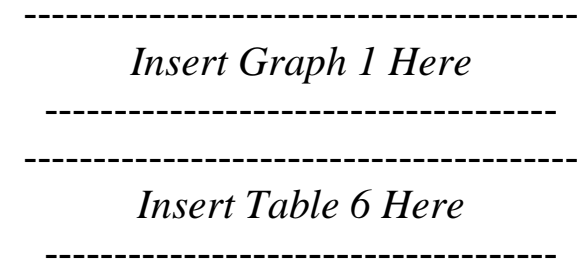

\section{Overexploration and market evolution}

Graph 2 shows that exploration and innovation performance have an inverted U-shaped relationship (Uotila et al., 2009; Yang and Li, 2011) for any level of market evolution. 
However, as can be observed, the tipping point in which the effect of exploration turns from increasing to decreasing occurs for higher values of exploration as the level of market evolution increases. This may mean that overexploration will be negative for all firms, but those that operate in a context characterized by a high pace of market evolution will be affected later. This pattern can be explained by the nature of a context in which the market evolves at a high pace. In such a context, the continuous fluctuations in product demand ensure that all products and services developed will have a space (Lumpkin and Dess, 2001). Therefore, firms developing exploration strategies will place the innovations that they have introduced easier if they operate in a context characterized by a high pace of market evolution, compared with a low market evolution context, in which there are fewer needs to satisfy. In keeping with this idea, those firms will take advantage of exploration strategies for a longer period, a fact that justifies that the negative effects associated with overexploration will appear for higher values of exploration. This idea is verified in Table 6, which indicates that, for high levels of market evolution, the tipping point is 1.681 , for medium levels, it is 1.435 , and for low levels, it is 1.190 .

Insert Graph 2 Here

\section{Overexploitation and market evolution}

In this later case, Graph 3 reveals that exploitation and innovation performance have a Ushape relationship, regardless of the level of market evolution. This result is consistent with the literature. For instance, Atuahene-Gima and Murray (2007) found that the relationship between exploitation and product innovation is U-shaped, denoting that overexploitation generate positive results. This may suggest that, as firms exploit more, they will obtain a higher innovation performance.

However, when the market is evolving at a high pace, the relationship between exploitation and innovation performance reaches its tipping point for lower levels of 
exploitation. This means that firms developing exploitation strategies will be able to exploit the benefits associated with these strategies sooner as the market evolution increases. One reason behind this could be that, in a context characterized by a high pace of market evolution, there are many market segments to be satisfied (Lumpkin and Dess, 2001). In such a context, the introduction of innovations based on small improvements may be better accommodated compared with a context in which the demand is rarely renewed (Raisch and Hotz, 2008). Therefore, the benefits associated with the development of exploitation strategies will outweigh the costs earlier when the market is evolving at a high pace. Table 6 corroborates that, as for high levels of market evolution the tipping point is $-0,877$, for medium levels, it is -0.441 , and for low levels it is -0.004 .

Insert Graph 3 Here

\section{CONCLUSION AND DISCUSSION}

The main purpose of this investigation has been to disentangle the impact of industry evolution on the relationships between exploration, exploitation and innovation performance. Although some scholars have studied this impact, to our knowledge they have always considered the dimensions that characterize industry evolution in an aggregate fashion (Jansen et al., 2006; Yamakawa et al., 2011). This is somewhat surprising given that the management literature has understood industry evolution as a multidimensional construct (Katz and Shapiro, 1992; Suárez and Lanzolla, 2007). Our paper has covered this gap by distinguishing two components of industry evolution, namely, the pace of market evolution and the pace of technology evolution, to analyze whether they have different impacts on the relationships between exploration and exploitation and innovation performance. In addition, we deepen the analysis of the curvilinear effects of exploration and exploitation, and how their relationship with innovation performance may be better understood when considering 
the level of technology and market evolution. This helps us to study the role that the evolution of the industry plays on the shapes of the relationships between overexploration, overexploitation and innovation performance.

Our results reveal that, in an environment characterized by rapid technology evolution, firms that develop exploration strategies can obtain better innovation performance. In contrast, we find that rapid technology evolution does not have any significant effect on the relationship between exploitation and innovation performance.

We also find that, when the market is evolving rapidly, the development of exploration and exploitation strategies leads to better innovation performance. Accordingly, the pace of market evolution seems to reward exploration and exploitation strategies equally. As is well known, rapid market evolution implies that there is always a demand to be satisfied (Raisch and Hotz, 2008). We argue that there will be both market segments that demand radical innovations (exploration) and market segments that require only improvements in the products and the services introduced (exploitation). Consequently, the innovations resulting from the development of exploration and exploitation strategies can both be accommodated in an environment characterized by rapid market evolution.

Our findings offer support to the premise that the pace of market evolution and the pace of technology evolution exercise different influences on the relationships between exploration, exploitation and innovation performance. On the one hand, although market and technology evolution point to the same direction in their relationship with exploration, this is not the case with exploitation, where technology evolution does not show any significant effect. On the other hand, the extension of the results provides additional evidence. In this section, we demonstrate that, as the level of technology or market evolution increases, the effects of overexploration are delayed, but not to the same extent. In addition, we found that, as the level of market evolution increases, the effects of overexploitation are anticipated. 
Our paper also aims to contribute to the exploration and exploitation literature (Rothaermel and Deeds, 2004), more precisely, to the stream of research that analyzes the boundary conditions on the relationship between these strategies and innovation performance (Jansen et al., 2006; Yang and Li, 2011). By decomposing industry evolution into two elements, the pace of market evolution and the pace of technology evolution, we offer a much more nuanced picture of how the evolution of an industry is related to both exploration and exploitation. Moreover, we believe that, by developing a more granular analysis of industry evolution, the literature on exploration and exploitation will follow the same path as other streams of research that have understood industry evolution as a multidimensional construct (McCarthy et al., 2010).

The paper also has important implications for practitioners. Based on our results, on one hand, firms operating in environments characterized by rapid technology evolution may benefit from the development of exploration strategies. On the other hand, firms that operate in a context characterized by rapid market evolution should be aware that the development of exploration and exploitation strategies is going to be related to higher performance.

Despite the contribution of our research to disentangling the impact of the two components of industry evolution on the relationship between exploration, exploitation and innovation performance, several issues will require additional attention. One is that, although we provide some evidence for the need to consider different components of the evolution of industry, we believe that more studies with alternative measures of market and technology evolution and other samples are needed. In this later case, since our database provides information about Spanish firms, our results are only representative of the behavior of the organizations operating in this country. That fact prevents us from generalizing our findings. Thus, as a future research line, we propose the extension of this analysis to other countries. Checking whether this phenomenon occurs in different scenarios could provide greater 
consistency to our findings. Another issue that deserves further attention is how to measure innovation performance. Due to data constraints, the variable we use in this study captures the success of product innovations, but the effect of a rapid pace of market evolution could also impact the efficiency of firms, which may also be related to process innovations. Thus, future research may explore different alternatives ways of incorporating process innovation into the discussion. 


\section{ACKNOWLEDGEMENTS}

We acknowledge financial support from the Spanish Ministry of Economy and Competitiveness and FEDER (project ECO2014-53904-R), the Regional Government of Aragón and FEDER (project S09) and Generés Research Group.

\section{REFERENCES}

Abernathy, W. J. and Utterback, J. M. 1978. "Patterns of industrial innovation." Technology Review 80(7): 40-47.

Aiken, L. S. and West, S. 1991. "Multiple regression: Testing and interpreting interactions".

Agarwal, R., Sarkar, M. and Echambadi, R. 2002. "The conditioning effect of time on firm survival: an industry life cycle approach." Academy of Management Journal 45(5): 971-94.

Amason, A. C., Shrader, R. C. and Tompson, G. H. 2006. "Newness and novelty: relating top management team composition to new venture performance." Journal of Business Venturing 21: 125-148.

Archibugi, D., Filippetti, A. and Frenz, M. 2013. "Economic crisis and innovation: is destruction prevailing over accumulation?" Research Policy 42: 302-14.

Armstrong, J. S. and Collopy, F. 1996. "Competitor orientation: effects of objectives and information on managerial decisions and profitability." Journal of Marketing Research 188-199.

Atuahene-Gima, K. 2005. "Resolving the capability-rigidity paradox in new product innovation." Journal of Marketing 69(4): 61-83.

Atuahene-Gima, K. and Murray, J. Y. 2007. "Exploratory and exploitative learning in new product development: a social capital perspective on new technology ventures in China." Journal of International Marketing 15(2): 1-29.

Auh, S. and Menguc, B. 2005. "Balancing exploration and exploitation: the moderating role of competitive intensity." Journal of Business Research 58: 1652-1661.

Barge-Gil, A. and López, A. 2014. "R\&D determinants: accounting for the differences between research and development." Research Policy 43(9): 1634-1648.

Bauer, M. and Leker, J. 2013. "Exploration and exploitation in product and process innovation in the chemical industry." R\&D Management 43(3): 196-212.

Beckman, C. M., Haunschild, P. R. and Phillips, D. J. 2004. "Friends or strangers? Firm-specific uncertainty, market uncertainty, and network partner selection." Organization Science 15(3): 259275.

Benner, M.J. and Tushman, M.L. 2003. "Exploitation, exploration, and process management: the productivity dilemma revisited." The Academy of Management Review 28: 238-256.

Cao, Q., Gedajlovic, E. R. and Zhang, H. 2009. "Unpacking organizational ambidexterity: dimensions, contingencies, and synergistic effects." Organization Science 20(4): 781- 796.

Cassiman, B. and Veugelers, R. 2006. "In search of complementarity in innovation strategy: internal R\&D and external knowledge acquisition." Management Science 52(1): 68-82.

Chatterjee, S., Hadi, A. and Price, B. 2000. "The use of regression analysis by example." 3d ed. New York: John Willey.

Clausen, T. H. and Pohjola, M. 2013. "Persistence of product innovation: comparing breakthrough and incremental product innovation." Technology Analysis \& Strategic Management 25(4): 369-385.

Crossan, M. M., Lane, H. W. and White, R. E. 1999. "An organizational learning framework: From intuition to institution." Academy of Management Review 24(3): 522-537.

Cusumano, M. A., Kahl, S. J. and Suarez, F. F. 2015. "Services, industry evolution, and the competitive strategies of product firms." Strategic Management Journal 36(4): 559-575.

Danneels, E. and Sethi, R. 2011. "New product exploration under environmental turbulence." Organization Science 22(4): 1026-1039.

Das, T. K. 2006. "Strategic alliance temporalities and partner opportunism." British Journal of Management 17(1): 1-22. 
Debenham, J. and Wilkinson, I. 2006. "Exploitation versus exploration in market competition." Industry and Innovation 13(3): 263-289.

D'Este, P., Marzucchi, A. and Rentocchini, F. 2017. "Exploring and yet failing less: learning from past and current exploration in R\&D." Industrial and Corporate Change, doi: 10.1093/icc/dtx044.

De Marchi, V. 2012. "Environmental innovation and R\&D cooperation: empirical evidence from Spanish manufacturing firms." Research Policy 41(3): 614-623.

Desai, M. A., Foley, C. F. and Hines, J. R. 2004. "A multinational perspective on capital structure choice and internal capital markets." The Journal of Finance 59(6): 2451-2487.

Dess, G. G. and Beard, D. W.1984. "Dimensions of organizational task environments." Administrative Science Quarterly 52-73.

Faems, D., Van Looy, B. and Debackere, K. 2005. "Interorganizational collaboration and innovation: toward a portfolio." Journal of Product Innovation Management 22(3): 238-250.

Filippucci, C., Drudi, I. and Papalia, R. B. 1996. "Testing the relevance of Tobin's approach for modelling consumption." Economic Notes 25(5): 225-248.

Fischer, T., Gebauer, H., Gregory, M., Ren, G. and Fleisch, E. 2010. "Exploitation or exploration in service business development? Insights from a dynamic capabilities perspective." Journal of Service Management 21(5): 591-624.

Fleming, L. and Sorenson, O. 2001. "Technology as a complex adaptive system." Research Policy 30: 1019-1039.

Galende, J. and Suárez, I. 1999. "A resource-based analysis of the factors determining a firm's R\&D activities.” Research Policy 28: 891-905.

Greene, K. 2000. "Technological innovation and economic progress in the ancient world: MI Finley re-considered." The Economic History Review 53(1): 29-59.

Greve, H. R. 2007. "Exploration and exploitation in product innovation." Industrial and Corporate Change (May) 1-31.

Grimpe, C. and Kaiser, U. 2010. "Balancing internal and external knowledge acquisition: the gains and pains from R\&D outsourcing." Journal of Management Studies 47(8): 1483-1509.

Gupta, A.K., Smith, K.G. and Shalley, C.E. 2006. "The interplay between exploration and exploitation." Academy of Management Journal 49: 693-706.

Haans, R. F., Pieters, C. and He, Z. L. 2016. "Thinking about U: Theorizing and testing U-and inverted U-shaped relationships in strategy research." Strategic Management Journal 37(7): 1177-1195.

He, Z.L. and Wong, P.K. 2004. "Exploration vs. exploitation: an empirical test of the ambidexterity hypothesis." Organization Science 15(4): 481-494.

Hendry, C. and Brown, J. 2006. "Organizational networking in UK biotechnology clusters." British Journal of Management 17(1): 55-73.

Isobe, T., Makino, S. and Montgomery, D. B. 2004. "Exploitation, exploration, and firm performance: the case of small manufacturing firms in Japan." Research collection, Lee Kong Chian School of Business, Singapore.

Jansen, J. J. P., Van Den Bosch, F. A. J. and Volberda, H. W. 2006. "Exploratory innovation, exploitative innovation, and performance: effects of organizational antecedents and environmental moderators." Management Science 52: 1661-1674.

Katila, R. and Ahuja, G. 2002. "Something old, something new: A longitudinal study of search behavior and new product introduction." Academy of Management Journal 45(6): 1183-1194.

Katz, M. L. and Shapiro, C. 1992. "Product introduction with network externalities." The Journal of Industrial Economics 40: 55-83.

Kim, T. and Rhee, M. 2009. "Exploration and exploitation: internal variety and environmental dynamism." Strategic Organization 7(1): 11-41.

Klepper, S. 1997. "Industry life cycles." Industrial and Corporate Change 6(1): 145-182.

Laursen, K. and Salter, A. 2006. "Open for innovation: the role of openness in explaining innovation performance among UK manufacturing firms." Strategic Management Journal 27(2): 131-150.

Lavie, D., Stettner, U. and Tushman, M. L. 2010. "Exploration and exploitation within and across organizations." Academy of Management Annals 4: 109-155. 
Levinthal, D. and March, J. 1993. "The Myopia of Learning." Strategic Management Journal 14: 95112.

López, A. 2011. "The effect of micro aggregation on regression results: an application to Spanish innovation data."

Love, J. H. and Roper, S. 2001. "Location and network effects on innovation success: evidence for UK, German and Irish manufacturing plants." Research Policy 30(4): 643-661.

Lumpkin, G. T. and Dess, G.G. 2001. "Linking two dimensions of entrepreneurial orientation to firm performance: the moderating role of environment and industry life cycle." Journal of Business Venturing 16: 429-451.

March, J. G. 1991. "Exploration and exploitation in organizational learning." Organization Science 2(1): 71-87.

McCarthy, I. P., Lawrence, T. B., Wixted, B. and Gordon, B. R. 2010. "A multidimensional conceptualization of environmental velocity." Academy of Management Review 35(4): 604-626.

Miotti, L. and Sachwald, F. 2003. "Co-operative R\&D: why and with whom?: An integrated framework of analysis." Research Policy 32(8): 1481-1499.

Mom, T. J., Van Den Bosch, F. A. and Volberda, H. W. 2007. "Investigating managers' exploration and exploitation activities: The influence of top down, bottom up, and horizontal knowledge inflows." Journal of Management Studies 44(6): 910-931.

Morgan, R.E. and Berthon, P. 2008. "Market orientation, generative learning, innovation strategy and business performance inter-relationships in bioscience firms." Journal of Management Studies 45(8): 1329-1353.

Mueller, V., Rosenbusch, N. and Bausch, A. 2013. "Success patterns of exploratory and exploitative innovation: a meta-analysis of the influence of institutional factors." Journal of Management 39(6): 1606-1636.

Nieto, M.J. and Santamaría, L. 2007. "The importance of diverse collaborative networks for the novelty of product innovation." Technovation 27: 367-377.

OECD (2005) Oslo Manual, Guidelines for collecting and interpreting innovation, 3rd edition, OECD, Paris.

O’Reilly, C. A. and Tushman, M. L. 2008. "Ambidexterity as a dynamic capability: Resolving the innovator's dilemma." Research in Organizational Behavior 28: 185-206.

Oriani, R. and Sobrero, M. 2008. "Uncertainty and the market valuation of R\&D within a real options logic.” Strategic Management Journal 29(4): 343-361.

Pellegrino, G. 2018. "Barriers to innovation in young and mature firms." Journal of Evolutionary Economics 28(1): 181-206.

Porter, M. E. 1980. "Competitive strategy: techniques for analyzing industries and competition." New York, 300.

Raymond, W., Mohnen, P., Palm, F., Van Der Loeff, S. S. 2010. "Persistence of innovation in Dutch manufacturing: Is it spurious?" The Review of Economics and Statistics 92(3): 495-504.

Raisch, S. and Hotz, F. 2008. "Shaping the context for learning: corporate alignment initiatives, environmental munificence, and firm performance." In S. Wall, C. Zimmermann, R. Klingebiel and D. Lange (Eds.), strategic reconfigurations: building dynamic capabilities in rapidinnovation-based industries 62-85

Rajagopalan, N. and Deepaic, K. 1996. "CEO characteristics: does industry matter?" Academy of Management Journal 39: 197-215.

Rawski, T.G. 1994. "Chinese industrial reform: accomplishments, prospects and implications." American Economic Review 84: 271-275.

Rosenkopf, L. and McGrath, P. 2011. "Advancing the conceptualization and operationalization of novelty in organizational research." Organization Science 22(5): 1297-1311.

Rosenkopf, L. and Nerkar, A. 2001. "Beyond local search: boundary-spanning, exploration, and impact in the optical disk industry." Strategic Management Journal 22(4): 287-306.

Rothaermel, F.T. 2001. "Incumbent's advantage through exploiting complementary assets via interfirm cooperation". Strategic Management Journal 22(6-7): 687-699.

Rothaermel, F. T. and Alexandre, M. T. 2009. "Ambidexterity in technology sourcing: The moderating role of absorptive capacity." Organization Science 20(4): 759-780. 
Rothaermel, F.T. and Deeds, D.L. 2004. "Exploration and exploitation alliances in biotechnology: a system of new product development." Strategic Management Journal 25(3): 201-221.

Sadowski, B. M. and Sadowski-Rasters, G. 2006. "On the innovativeness of foreign affiliates: evidence from companies in The Netherlands." Research Policy 35(3): 447-462.

Schmidt, J. B. and Calantone, R. J. 1998. "Are really new product development projects harder to shut down?" Journal of Product Innovation Management 15(2): 111-123.

Sharfman, M. P. and Dean Jr, J. W. 1991. "Conceptualizing and measuring the organizational environment: A multidimensional approach.” Journal of Management 17(4): 681-700.

Sidhu, J.S., Commandeur, H.R. and Volberda, H.W. 2007. "The multifaceted nature of exploration and exploitation: value of supply, demand, and spatial search for innovation." Organization Science 18: 20-38.

Sorensen, J.B. and Stuart, T.E. 2000. "Aging, obsolescence and organizational innovation." Administrative Science Quarterly 45: 81-113.

Suárez, F.F. and Lanzolla, G. 2007. "The role of environmental dynamics in building a first mover advantage theory." Academy of Management Review 32(2): 377-392.

Tsai, K. H. 2009. "Collaborative networks and product innovation performance: toward a contingency perspective." Research Policy 38(5): 765-778.

Tushman, M. L. and Anderson, P. 1986. "Technological discontinuities and organizational environments." Administrative Science Quarterly 31(3): 439-465.

Uotila, J., Maula, M.V.J., Keil, T. and Zahra, S.A. 2009. "Exploration, exploitation, and financial performance: analysis of S\&P 500 corporations." Strategic Management Journal 30: 221-231.

Utterback J. 1994. "Mastering the Dynamics of Innovation". Harvard Business School Press: Boston, MA.

Vega Jurado, J., Gutiérrez Gracia, A. and Fernández de Lucio, I. 2009. "La relación entre las estrategias de innovación: coexistencia o complementariedad." Journal of Technology Management \& Innovation 4(3): 74-88.

Wang, H. and $\mathrm{Li}, \mathrm{J}$. 2008. "Untangling the effects of overexploration and overexploitation on organizational performance: the moderating role of environmental dynamism." Journal of Management 34(5): 925-951.

Wind, J. and Mahajan, V. 1997. "Issues and opportunities in new product development: an introduction to the special issue." Journal of Marketing Research 34: 1-12.

Woerter, M. and Roper, S. 2008. "Openness and innovation-home and export demand effects on manufacturing innovation: panel data evidence for Ireland and Switzerland."

Yalcinkaya, G., Calantone, R.J. and Griffith, D.A. 2007. "An examination of exploration and exploitation capabilities: implications for product innovation and market performance." Journal of International Marketing 15(4): 63-93.

Yamakawa, Y., Yang, H. and Lin, Z. 2011. "Exploration versus exploitation in alliance portfolio: performance implications of organizational, strategic, and environmental fit." Research Policy 40: $287-296$.

Yang, T.T. and Li, C.R. 2011. "Competence exploration and exploitation in new product development: the moderating effects of environmental dynamism and competitiveness." Management Decision 49(9): 1444-1470.

Zahra, S.A. 1996. "Technology strategy and financial performance: examining the moderating role of the firm's competitive environment." Journal of Business Venturing 11: 189-219.

Zahra, S.A. and Bogner, W.C. 1999. "Technology strategy and software new venture's performance: exploring effect of the competitive environment." Journal of Business Venturing 15: 135-173. 
TABLES

Table 1. Distribution of firms by industry and technological level

\begin{tabular}{ccc}
\hline Manufacturing & Number of firms & $\%$ \\
\hline High technology & 6,635 & 28.83 \\
Low technology & 7,925 & 34.43 \\
\hline Total & 14,560 & 63.26 \\
& & \\
\hline Services & Number of firms & $\%$ \\
\hline High technology & 2,507 & 10.89 \\
Low technology & 5,948 & 25.84 \\
\hline Total & 8,455 & 36.74
\end{tabular}

Table 2. Distribution by size of the firms in the sample

\begin{tabular}{ccc}
\cline { 2 - 3 } & $\mathrm{N}$ & $\%$ \\
\hline Micro-enterprises & 2,099 & 9.12 \\
Small enterprises & 8,902 & 38.68 \\
Medium enterprises & 7,428 & 32.27 \\
Large enterprises & 4,586 & 19.93 \\
\hline
\end{tabular}

Table 3. Factor analysis

Objectives for undertaking innovation projects

Exploitation Exploration

$(1=$ not important a $3=$ very important $)$

Extent product range

$0.106 \quad \mathbf{0 . 8 2 6}$

Introduce new generation of products

0.315

0.647

Open up new markets

0.192

0.842

Improve market share

0.236

0.856

Improve existing product quality

0.305

0.755

Improve production flexibility

0.749

0.189

Improve capacity of production or service delivery

0.778

0.231

Reduce labor costs per unit produced

0.834

0.240

Reduce material per unit produced

0.806

0.223

Reduce energy per unit produced

0.808

0.206

Cronbach alpha

0.886

0.896

Notes. Extraction method: Principal component analysis

Rotation method: Varimax with Kaiser normalization 
Table 4. Descriptive statistics and correlation matrix

\begin{tabular}{|c|c|c|c|c|c|c|c|c|c|c|c|c|c|c|}
\hline Variables & $\mathrm{n}$ & Mean & Std. Dev & Min & Max & (1) & $(2)$ & (3) & (4) & (5) & $(6)$ & (7) & $(8)$ & (9) \\
\hline Innovation performance & 23,015 & 0.202 & 0.253 & 0 & 0.693 & 1 & & & & & & & & \\
\hline Exploration & 23,015 & -0.001 & 0.999 & -2.746 & 1.839 & 0.202 & 1 & & & & & & & \\
\hline Exploitation & 23,015 & 0.004 & 0.999 & -2.114 & 2.467 & 0.020 & 0.002 & 1 & & & & & & \\
\hline Technology evolution (000) & 23,015 & 4.216 & 8.138 & 0.009 & 70.146 & 0.045 & 0.092 & 0.016 & 1 & & & & & \\
\hline Market evolution & 23,015 & 0.941 & 0.169 & 0.524 & 1.844 & -0.029 & 0.026 & -0.007 & -0.023 & 1 & & & & \\
\hline International activity & 23,015 & 0.240 & 0.308 & 0 & 1 & 0.059 & 0.114 & 0.099 & 0.077 & -0.017 & 1 & & & \\
\hline Participation of foreign capital & 23,015 & 0.135 & 0.342 & 0 & 1 & -0.013 & -0.017 & 0.062 & 0.033 & 0.021 & 0.156 & 1 & & \\
\hline Innovation intensity $(000)$ & 23,015 & 5.749 & 13.367 & 0 & 470.793 & 0.119 & 0.179 & 0.011 & 0.373 & 0.014 & 0.067 & -0.018 & 1 & \\
\hline Size $(000)$ & 23,015 & 0.306 & 1.394 & 1 & 40.504 & -0.011 & -0.010 & 0.044 & -0.031 & 0.018 & -0.035 & 0.101 & -0.042 & 1 \\
\hline
\end{tabular}


Table 5. Relationship between exploration and exploitation and innovation performance

\begin{tabular}{|c|c|c|c|}
\hline & $\begin{array}{c}\text { (1) } \\
\text { Innovation } \\
\text { performance }\end{array}$ & $\begin{array}{c}(2) \\
\text { Innovation } \\
\text { performance }\end{array}$ & $\begin{array}{c}\text { (3) } \\
\text { Innovation } \\
\text { performance }\end{array}$ \\
\hline Exploration & & $\begin{array}{c}0.0715^{* * *} \\
(15.16)\end{array}$ & $\begin{array}{l}0.0746^{* * *} \\
(15.32)\end{array}$ \\
\hline Exploitation & & $\begin{array}{c}0.0100^{* *} \\
(2.51)\end{array}$ & $\begin{array}{c}0.0115^{* * *} \\
(2.81)\end{array}$ \\
\hline Exploration-squared & & $\begin{array}{c}-0.0240^{* * *} \\
(-6.06)\end{array}$ & $\begin{array}{c}-0.0254^{* * *} \\
(-6.35)\end{array}$ \\
\hline Exploitation-squared & & $\begin{array}{c}0.0116^{* * *} \\
(3.40)\end{array}$ & $\begin{array}{l}0.0117^{* * *} \\
(3.40)\end{array}$ \\
\hline Technology evolution (000) & & & $\begin{array}{c}-0.000118 \\
(-0.12)\end{array}$ \\
\hline Technology evolution*Explor & $(000)$ & & $\begin{array}{c}0.00173^{* *} \\
(2.56)\end{array}$ \\
\hline Technology evolution*Exploi & $(000)$ & & $\begin{array}{l}0.000408 \\
(0.87)\end{array}$ \\
\hline Market evolution & & & $\begin{array}{r}0.0130 \\
(0.42)\end{array}$ \\
\hline Market evolution*Exploration & & & $\begin{array}{c}0.0454^{*} \\
(1.78)\end{array}$ \\
\hline Market evolution*Exploitation & & & $\begin{array}{r}0.0356^{*} \\
(1.68)\end{array}$ \\
\hline International activity & $\begin{array}{l}0.0516^{* * *} \\
(3.57)\end{array}$ & $\begin{array}{l}0.0392^{* * *} \\
(2.75)\end{array}$ & $\begin{array}{l}0.0391^{* * *} \\
(2.75)\end{array}$ \\
\hline $\begin{array}{l}\text { Participation of foreign } \\
\text { capital }\end{array}$ & 0.0034 & 0.0075 & 0.0072 \\
\hline Innovation intensity $(000)$ & $\begin{array}{c}(0.25) \\
0.0018^{* * *} \\
(5.80)\end{array}$ & $\begin{array}{c}(0.56) \\
0.0011^{* * *} \\
(3.71)\end{array}$ & $\begin{array}{c}(0.54) \\
0.0012^{* * *} \\
(3.75)\end{array}$ \\
\hline Size (000) & $\begin{array}{c}0.0092^{* *} \\
(2.31)\end{array}$ & $\begin{array}{c}0.00646^{*} \\
(1.66)\end{array}$ & $\begin{array}{c}0.00635 \\
(1.63)\end{array}$ \\
\hline Constant & $\begin{array}{c}-0.0987 \\
(-0.38)\end{array}$ & $\begin{array}{c}-0.1312 \\
(-0.52)\end{array}$ & $\begin{array}{l}-0.1323 \\
(-0.52)\end{array}$ \\
\hline $\begin{array}{l}\text { Temporal dummies } \\
\text { Sectorial dummies }\end{array}$ & $\begin{array}{l}\text { Yes } \\
\text { Yes }\end{array}$ & $\begin{array}{l}\text { Yes } \\
\text { Yes }\end{array}$ & $\begin{array}{l}\text { Yes } \\
\text { Yes }\end{array}$ \\
\hline $\begin{array}{r}\mathrm{N} \\
\mathrm{N}^{\mathrm{o}} \text { of firms } \\
\text { Log Likelihood } \\
\text { Wald chi-square } \\
\text { Test vs. 1 } \\
\text { Test vs. 2 } \\
\text { AIC }\end{array}$ & $\begin{array}{c}15,286 \\
6631 \\
-9,332.75 \\
688.30^{* * *}\end{array}$ & $\begin{array}{c}15,286 \\
6631 \\
-9117.60 \\
1,089.09^{* * *} \\
417.45^{* * *}\end{array}$ & $\begin{array}{c}15,286 \\
6631 \\
-9,111.23 \\
1,099.13^{* * *} \\
428.54^{* * *} \\
12.59^{* *} \\
18,340.48\end{array}$ \\
\hline
\end{tabular}


Table 6. Tipping point for different levels of technology and market evolution

\begin{tabular}{lcccccc}
\cline { 2 - 6 } & \multicolumn{3}{c}{ Technology evolution } & \multicolumn{3}{c}{ Market evolution } \\
\hline & high & medium & low & high & medium & low \\
\hline Exploration & 2.031 & 1.466 & 0.901 & 1.681 & 1.435 & 1.190 \\
Exploitation & - & - & - & $-0,877$ & -0.441 & -0.004 \\
\hline
\end{tabular}




\section{GRAPHS}

Graph 1. Relationship between exploration and innovation performance for different values of technology evolution

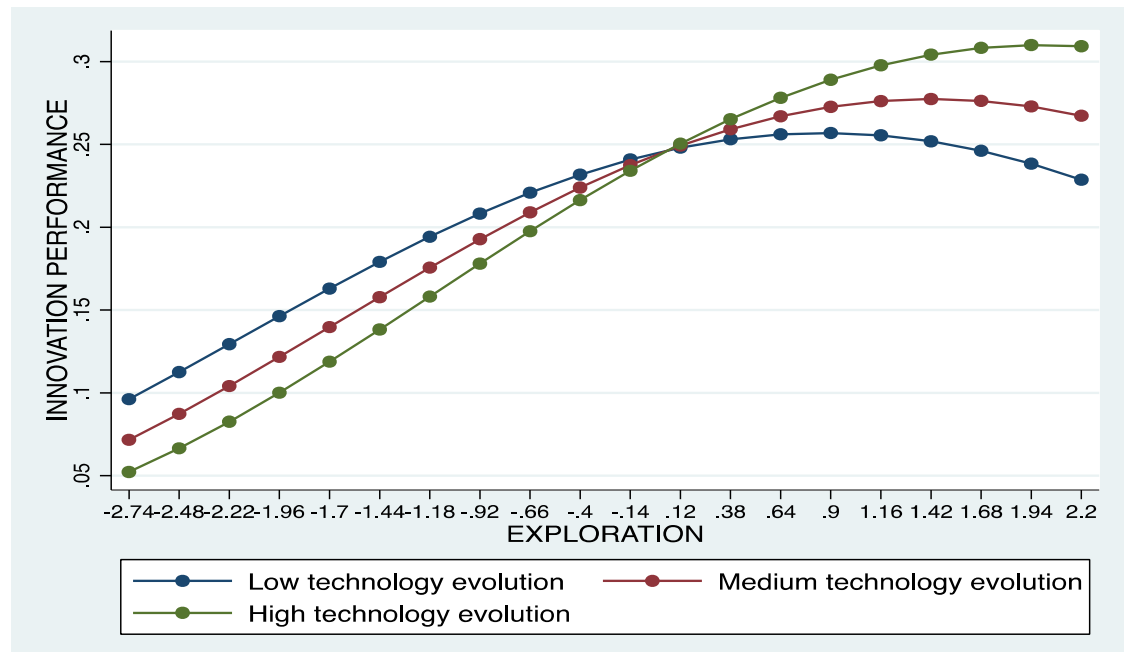

Graph 2. Relationship between exploration and innovation performance for different values of market evolution

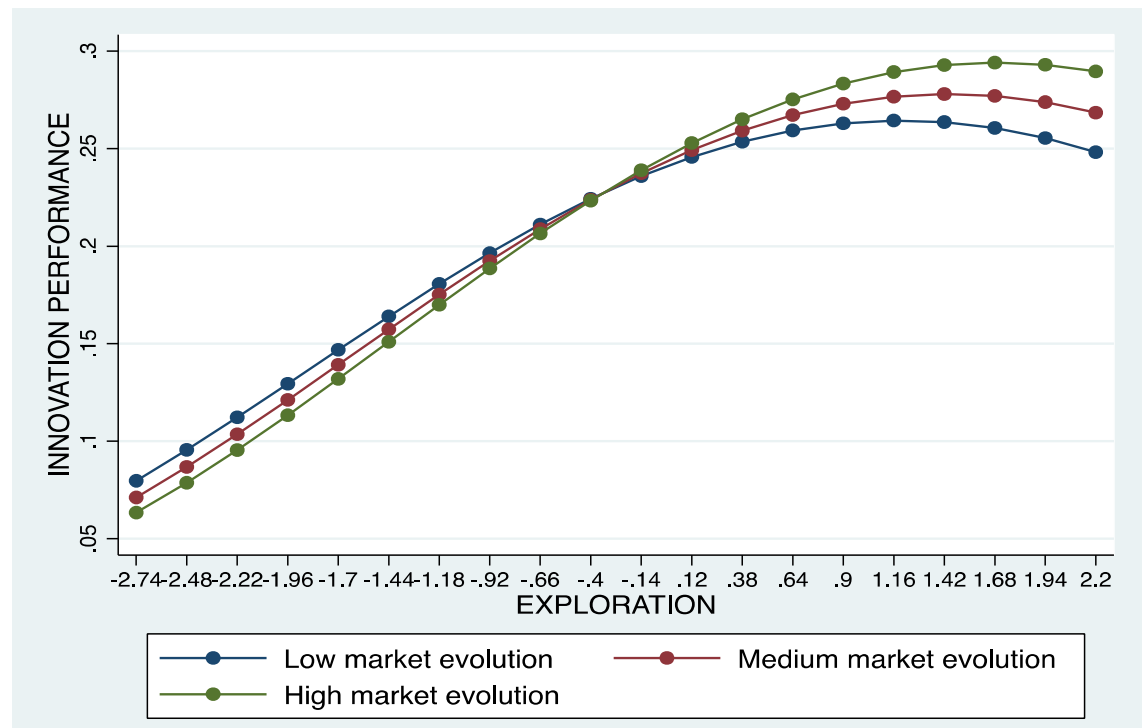


Graph 3. Relationship between exploitation and innovation performance for different values of market evolution

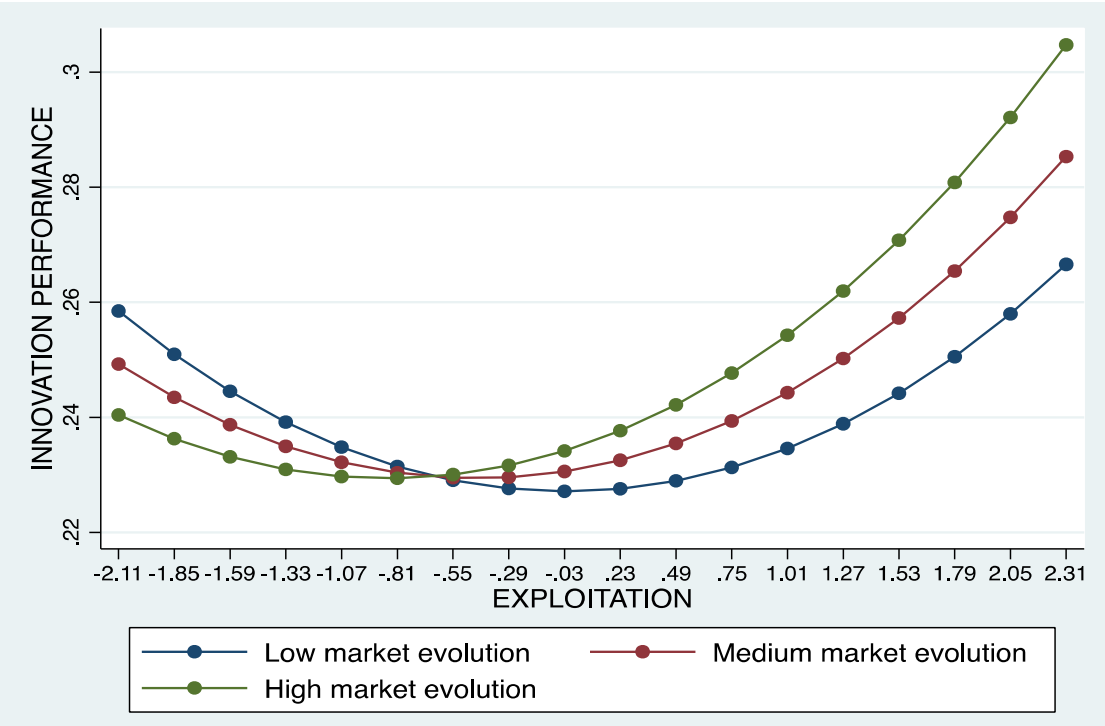

